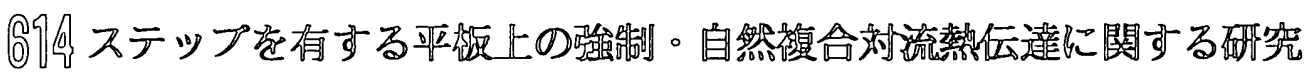

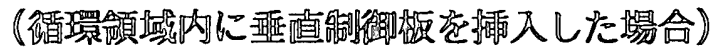

A Fundamental Study on Combined Free and Forced Convective Heat Transfer from a Vertical plate followed by a Backward Step.

(Setting Vertical Control Plate in Circulating Flow Region)

八田 政治，宮西 広樹，鈴木 淳，岸浪 紘機，戸倉 郁夫 （室蘭工業大学）

Masaharu Hatta , Hiroki Miyanishi, Jyun Suzuki, Koki Kishinami, Ikuo Tokura, Muroran Institute of Technology

\section{1。䂂 言}

ステップを有する垂直面上の強制・自然複合対流熱伝澾現象は, はく離・循環·再付着を伴い，その熱伝達举動は浮力と憒性力の相互 干涉の結果, 形状因子等と重なり複雑なものとなり，ある特定の条 件においては流れの不安定自励振動的挙動を生ずることが判明して いる。本研究は、従来のはく離・循環・再付着を伴う複合対流熱伝 達に関する研究を基にし, ステップ面上に生じる循環領域が対流挙 動に大きな影響を与えることから，簡易な制御板をステッフ面循環 流領域内に挿入した場合の熱伝達制御の可能性について, 理論的・ 実験的な見地から，明らかにすることを目的とする。

\section{缩用記昜}

$\mathrm{d}$ : ステッフ長さ， $\mathrm{L}:$ 代表長さ， $\mathrm{L}_{\mathrm{c}}$ : 制御板長さ， $\mathrm{h}$ : 熱伝達率, $\mathrm{t}:$ 温度,

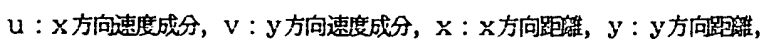

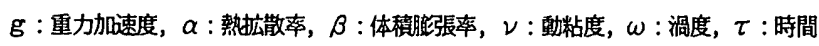

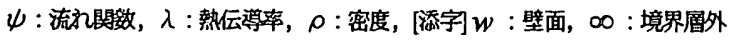

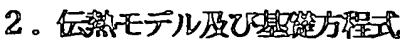

Fig.1 に実験装置概要及び Fig.2 に物理モデルを示す。図中 X 軸 は重力と平行に, $\mathrm{Y}$ 軸は垂直方向にとる. 伝熱面全面は $\mathrm{t}_{\mathrm{w}}$ に等温 加熱され，主流速度 $U_{\infty}$ に置かれている。後段垂直部 (2-1 面) は, ステップ高さ d及ひ前段長さLに比へて十分長いものとする.なお， 壁面からの放射熱流は鏡面壁として考虑しないものとする。本研究 において取り扱う無次元変数を，以下のように定義する。

$$
\begin{aligned}
& X=\frac{x}{L}, Y=\frac{y}{L}, U=\frac{u}{U_{\infty}}, V=\frac{v}{U_{\infty}}, T=\frac{t-t_{\infty}}{t_{w}-t_{\infty}} \\
& \Omega=\frac{L \omega}{U_{\infty}}, \Psi=\frac{\psi}{U_{\infty} L}, \tau^{*}=\frac{\tau U_{\infty}}{L}, \operatorname{Pr}=\frac{v}{\alpha}, \operatorname{Re}_{L}=\frac{U_{\infty} L}{v} \\
& G r_{L}=\frac{g \beta\left(t_{m}-t_{\infty}\right) L^{3}}{v^{2}}, N u_{L}=\frac{h L}{\lambda}=-\left(\frac{\partial T}{\partial Y}\right)_{Y=0}
\end{aligned}
$$

渦度法に依る渦輸送方程式及びエネルギ式に，上の強制㳔流型無 次元変数を導入すれば, 次の基礎方程式が得られる。

$$
\begin{aligned}
& \frac{\partial U}{\partial X}+\frac{\partial V}{\partial Y}=0, U=\frac{\partial \Psi}{\partial Y}, V=-\frac{\partial \Psi}{\partial X}, \Omega=\frac{\partial^{2} \Psi}{\partial X^{2}}+\frac{\partial^{2} \Psi}{\partial Y^{2}} \\
& \frac{\partial T}{\partial \tau^{\circ}}+U \frac{\partial T}{\partial X}+V \frac{\partial T}{\partial Y}=\frac{1}{\operatorname{PrRe}_{L}}\left(\frac{\partial^{2} T}{\partial X^{2}}+\frac{\partial^{2} T}{\partial Y^{2}}\right) \\
& \frac{\partial \Omega}{\partial \tau^{\circ}}+U \frac{\partial \Omega}{\partial X}+V \frac{\partial \Omega}{\partial Y}=\frac{G r_{L}}{\operatorname{Re}_{L}^{2}} \frac{\partial T}{\partial Y}+\frac{1}{\operatorname{Re}_{L}}\left(\frac{\partial^{2} \Omega}{\partial X^{2}}+\frac{\partial^{2} \Omega}{\partial Y^{2}}\right)
\end{aligned}
$$

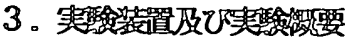

Fig.1 より, 伝熱面は, 厚さ $5 \mathrm{~mm}$ のアルミ板と, 裹部厚さ $10 \mathrm{~m}$ $\mathrm{m}$ のベークライト板から成り, 前段部, ステップ部, 後段部の 3 部 に分割し, 後段部は更に 4分割し電気通電により加熱した. その際, 直径 $0.26 \mathrm{~mm}$ のニクロム線をアルミ板とベークライト板の間に交 互配列状に 6 ケ所取り付けた. 主流速度は可変速モ一夕直結のプロ ペラ駆動により得られ，整流板を通した。壁面温度測定の場合は直 径 $0.1 \mathrm{~mm}$ 熱電対をアルミ板表面に計 6 ケ所設置し測定した。

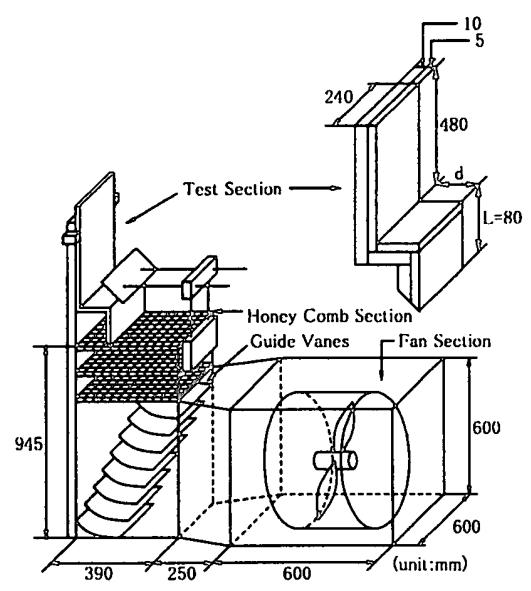

Fig.1 Experimental Apparatus

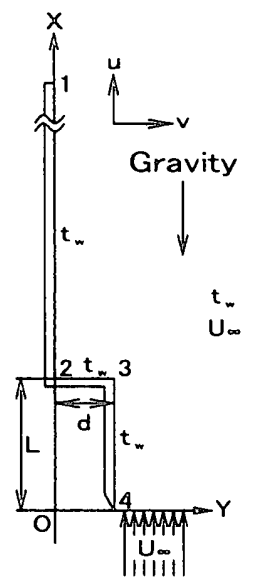

Fig.2 Physical Model

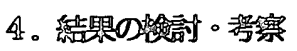

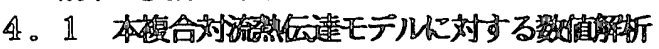

数值解析を行なうにあたり，人工粘性（数值粘性）は慣性対流項 の風上差分を実施する場合に必ず伴う䛊差である。本研究では，こ の人工粘性問題がかなりの程度で回避でき, 計算費用, 精度, 安定 性を考愿した上で，最適と考えられるべき乗法を適用した。また， 流れの解析に用いる対流方程式は非線形性力強く，繰り返し計算に おいて直接予測值を用いれば不安定になりやすい。これを回避し， 収束解を得るため，緩和因子とを導入して収束を加速した。時間進 行 $\Delta \tau$ における収束条件は, $\mathrm{m}$ 回目の計算値と $\mathrm{m}+1$ 回目の計算值 との最大誤差を $\pm 3.0 \times 10^{-2}$ に設定した。また，本年度の数值解析 では，制御㤆上の流孔関数の与え方を厳密化した。その結果，対流 挙動の振動を抑制し，早い時間で収束解を得ることで，計算時間が 短縮された。

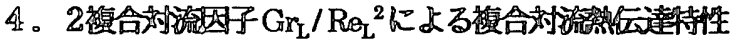

ここで, $\mathrm{Gr}_{\mathrm{L}} / \mathrm{Re}_{\mathrm{L}}{ }^{2}=\mathrm{g} \beta\left(\mathrm{t}_{\mathrm{w}}-\mathrm{t}_{\infty}\right) \mathrm{L} / \mathrm{U}_{\infty}{ }^{2}$ は, 強制対流と自然対流 の影響の比を表すパラメータであり，この值が小さいほと強制対流 が，大きいほど自然対流が支配的な場となることを表している。

Fig.3 は，本複合対流熱伝達において，強制対流が支配的な場合か ら，自然対流が支配的な場合几移行したときの流線分布を示してい る. また, これらの条件と対応する温度分布を Fig.4に，局所熱伝 達率分布を Fig.5 に示す。Fig.3 より，強制刘流が支配的な場合 (a) では，壁面に沿う時計回りの渦流が大きく，自然対流が支配的な場 合 (c) では, 主流に沿う反時言十回りの瀜流が大きくなる。これに 対し, 強制対流と自然対流の影響がほぼ同等である場合 (b) では, この二つの逆まわりの渦流は, 殆ど同じ割合でステップ面上に存在 する。また, 自然対流の影響か強くなる程慣性力が小さくなるので， 再付着点がステップ面方向に移動して循環領域を狭める方向に作用 している. Fig.4より, $\mathrm{Gr}_{\mathrm{L}} / \mathrm{Re}_{\mathrm{L}}{ }^{2}$ が大きくなれば, 循環領域内に存 在する洞流が強くなり，ステップ面上と後段垂直面上の等温線の間 隔が狭くなる。Fig.5 は局所熱伝達率分布を示すが，一般に等温線 の間隔が広い部分では熱伝達率が低くなり，怗い部分では高くなる ので, $\mathrm{Gr}_{\mathrm{L}} / \mathrm{Re}_{\mathrm{L}}{ }^{2}$ の大きい程局所熱伝達率は大きくなる。 


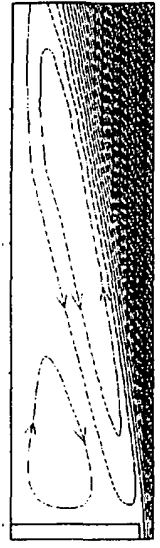

(a)

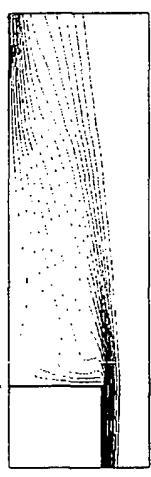

(a)

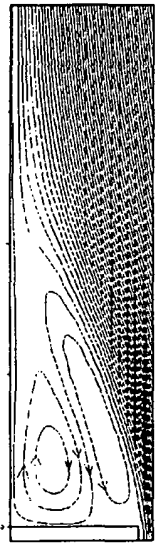

(b)

Fig.3 Stream Line

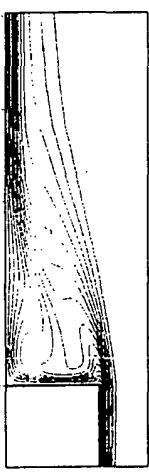

(b)

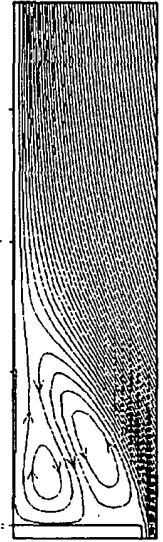

(c) (a) $\mathrm{Gr}_{\mathrm{I}} / \operatorname{ReL}^{2}=0.11$ $\mathrm{U}_{\infty}=0.5[\mathrm{~m} / \mathrm{s}]$ $\mathrm{T}_{\mathrm{W}}=30.0 \quad\left[{ }^{\circ} \mathrm{C}\right]$

(b) $\mathrm{Gr} / \operatorname{ReL}^{2}=\mathbf{0 . 5 9}$ $\mathrm{U}_{\infty}=0.3[\mathrm{~m} / \mathrm{s}]$ $\mathrm{T}_{\mathrm{W}}=40.0\left[{ }^{\circ} \mathrm{C}\right]$

(c) $\mathrm{Gr} / \operatorname{ReL}^{2}=3.34$ $\mathrm{U}_{\infty}=0.2[\mathrm{~m} / \mathrm{s}$ $\mathrm{TW}=70.0\left[{ }^{\circ} \mathrm{C}\right]$

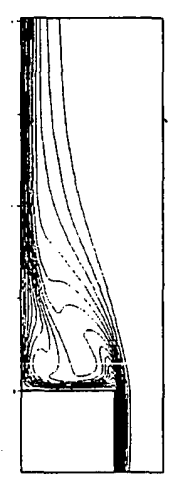

(a) $\mathrm{Gr} / \operatorname{Re}_{L}{ }^{2}=0.11$ $\mathrm{U}_{\infty}=0.5[\mathrm{~m} / \mathrm{s}]$ $\mathrm{Tw}=30.0 \quad\left[{ }^{\circ} \mathrm{C}\right]$

(b) $\operatorname{GrJ} / \operatorname{Re}_{L}{ }^{2}=0.59$ $\mathrm{U}_{\infty}=0.3[\mathrm{~m} / \mathrm{s}]$ $\mathrm{T} \mathrm{W}=40.0\left[{ }^{\circ} \mathrm{C}\right]$

(c) $\mathrm{GrJ} / \operatorname{Re}^{2}=3.34$ $\mathrm{U}_{\infty}=0.2[\mathrm{~m} / \mathrm{s}]$ $\mathrm{TW}=70.0\left[{ }^{\circ} \mathrm{C}\right]$

Fig.4 Temperature Field

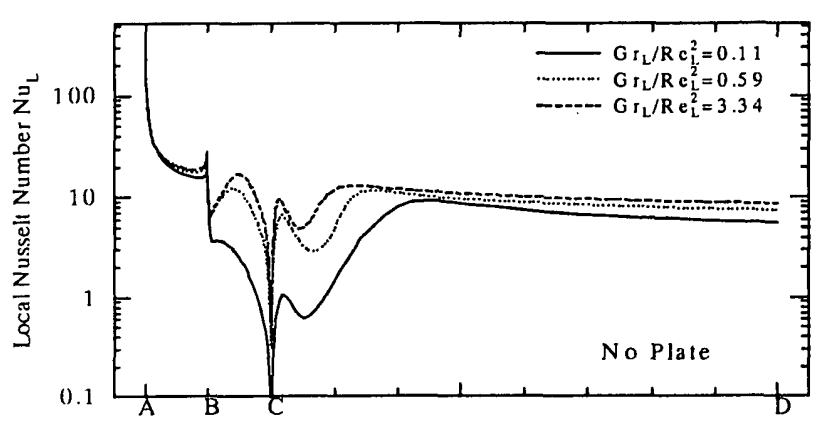

Fig.5 Distribution of Local Nusselt Number

\section{3 垂直制胙帊を設置した複合対流热伝達特性}

Fig.6は, $\mathrm{Gr}_{\mathrm{r}} / \mathrm{ReL}^{2}=0.59, \mathrm{U}_{\infty}=0.3[\mathrm{~m} / \mathrm{s}], \quad \mathrm{Tw}=40.0\left[{ }^{\circ} \mathrm{C}\right]$ の条件における，制御板のない場合と，ステップ面から制御板下端 までの $\mathrm{X}$ 方向無次元距離 IZ $=0.3$, 後段垂直面から制御板側面までの $\mathrm{Y}$ 方向無次元距離 $\mathrm{JZ}=0.5 \mathrm{D} / \mathrm{L}$ の位置に長さ $\mathrm{L}_{\mathrm{C}}=0.5$ の垂直制御板 を設置した場合の流線分布を示している．同様に温度分布を Fig.7 に，局所熱伝達率分布を Fig.8 に示す. Fig.6 より，ステップ面中心 上への垂直制御板の設置により，主流の影響が制御板内側に伝わり にくく，制御板内側で流れが緩慢となる．これに対し，主流に治う 反時計回りの渦流は制御板を取り込む様に流れる，結果，渦流は大 きくなる. Fig.7 より，制御板の設置により制御板内側とステップ 面上で等温線間隔が広くなる，これは，制御板を設置すると制御板 内側とステップ面上では流れか弱まり, 更に, 制御板の存在か流れ を遮蔽して熱を通さず，加熱平板より発する熱が制御板内側でのみ 循環するため，制御板内側の領域が高温化する．これより，局所熱 伝達率は Fig.8 に示すように，制御板内側とステップ面上では低い 熱伝達率となる. Fig.9 に，同一条件における，制御板のない場合 と設置した場合の平均熱伝達率を示す，図より，制御板のない場合 では振動的であるが，制御板の設置によりその挙動は安定化する.
これは, 制御板を設置による粘性增大効果により渦流の不安定さが 抑制され，最も対流挙動が振動しやすい $\mathrm{Gr} / \mathrm{ReL}^{2}=0.59$ の条件で も安定した熱伝達挙動となるが, 必ずしも系全体の熱伝達の改善に つながるとは限らない。
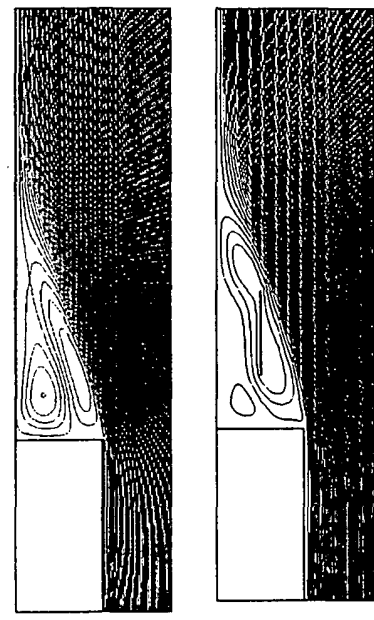

Fig.6 Stream Line
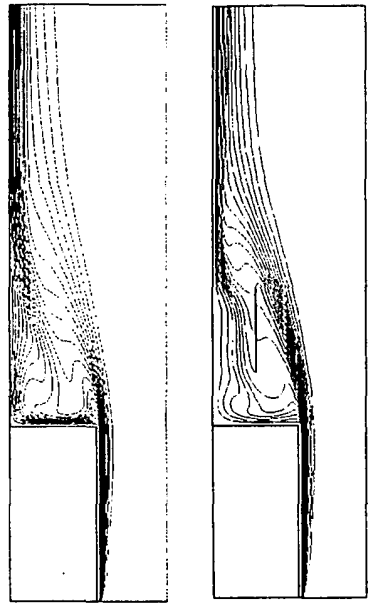

Fig.7 Temperature Field

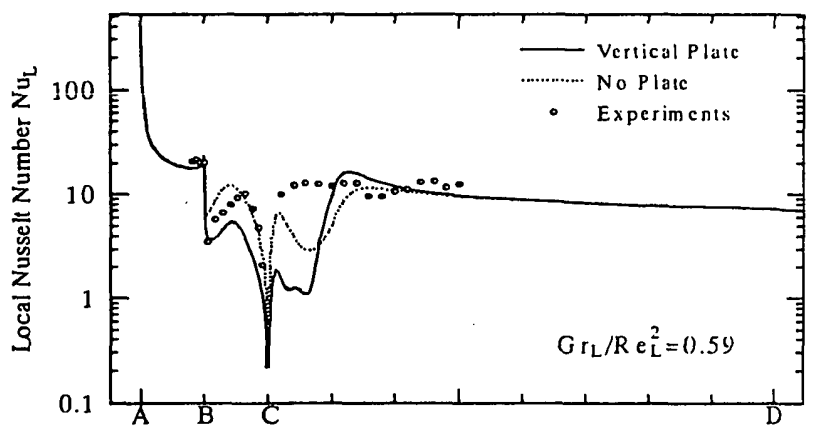

Fig.8 Distribution of Local Nusselt Number

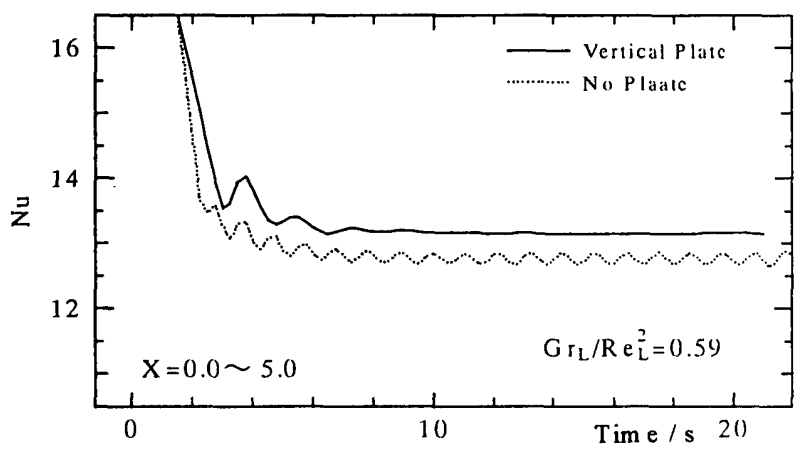

Fig.9 Average Nusselt Number

5. 結 言

本研究により得られた結果を以下に記す.

（1）複合対流因子 $\mathrm{Gr} / \operatorname{Re}^{2}=0.59$ 近傍の条件では, 自然対流之強 制対流の影響がほぼ均衡しており，そのどちらかの影響が強い状態 に推移しやすい不安定な状態なため, 再付着点近傍に大きな不安定 挙動が現れ，全体としても周期的に変動する熱伝達举動となる.

（2）垂㨁制御板の設置により，制御板内側では遮蔽効果と粘性増 大効果があり, 渦流の強さが軽減・安定化され, 緩慢な流れ場とな り，結果として高温域となり，ステップ面上及び制御板内側の局所 熱伝详率はかなり低下する. また，垂直制御板の設置により，局所 的に熱伝達を促進させることは可能であり, 渦流の強さが抑制され， 熱伝達挙動は一般的に安定したものとなる.

\section{参考文献}

[1] 岸浪, 梅木 - 他, International Journal of Methods for Heat \& Fluid Flow Vol . 8 No .6 (1998) pp.717-736. 